\title{
Dynamic resonance and social reciprocity in language change: The case of Good morrow
}

\begin{abstract}
:
Entrenchment (i.e. Langacker 1987) does not necessarily lead to predictable behaviour. This study aims at complementing the usage-based model of language change by operationalising the role of dialogic creativity as a mechanism that can be in competition with conventionalization and grammaticalization. We provide a distinctive collexeme analysis (i.e. Hilpert 2006) focusing on the constructionalization of the dialogic pair [A: good morrow B - B: (good) morrow (A)] from the 15th up to the 18th century. After reaching the highest degree of entrenchment and automatisation, the dialogic pair will show an increasing tendency to be creatively re-modelled with ad-hoc meanings during online exchanges by means of dynamic resonance (Du Bois 2014) and non-reciprocal behaviour. We define this creative process of large-scale alteration as entrenchment inhibition. From our data it will emerge that entrenchment inhibition is triggered by spontaneous attempts of producing a creative 'surplus' over the expected social reciprocity (Gouldner 1960) of conventionalized exchanges. This tendency will be shown to be driven by marked attempts of polite and impolite behaviour.
\end{abstract}

Keywords: entrenchment inhibition; reciprocity; dynamic resonance; politeness; constructionalization; re-composition

\section{Introduction}

Most usage-based accounts focusing on language change in the form of constructional (inter)subjectification (i.e. De Smet \& Verstraete; Traugott 2010; Narrog 2012, Nuyts 2012; Traugott \& Trousdale 2013; Tantucci 2017) are primarily concerned with tendencies towards the repetition and the predictability of verbal experience. Phenomena such as entrenchment (cf. Langacker 1987: 59; Croft 2000: 38; Zima \& Brone 2015: 488), increase of schematicity (i.e. Bybee 2010; Traugott \& Trousdale 2013: 22), chunking (i.e. Bybee 2010) and conventionalization (cf. Terkourafi 2015) are just a few examples of the emphasis that is given to the diachronic relationship between rituality and abstraction of constructions and linguistic exchanges. 
The present study similarly endorses the view of language as an adaptive system (cf. Beckner et al. 2009) that moves towards the uniformity, rituality and predicability (cf. Bybee 2010) of its items. Yet, we crucially aim at complementing the so-called usage-based model by also taking into account individuals' creative inhibition of entrenched constructions during speech events. Diachronic corpus-based/driven evidence and experimental research from the literature convincingly beat the drum for models of the linguistic system moving toward the automatic processing of repeatedly codified chunks from verbal exchanges (i.e. Bybee 2010; Blythe \& Croft 2012; Kuperman \& Bresnan 2012). Yet, in the present study we suggest that the diachronic formation of such patterns does not necessarily trigger a blind reiteration of the same forms. Rather, typically (rather than occasionally) individuals seem to engage with prototypical patterns by altering their internal constituency or by intervening with their usage with less predictable pragmatic strategies. We define this phenomenon as entrenchment inhibition, viz. the creative manipulation of a schematic/entrenched chunk of experience: i.e. greetings such as see you next time (BNC J8J 483) or see you a bit later (BNC KCP 3993 ) in the place of the more idiomatic see you later.

From a diachronic perspective, this approach represents a new angle from which to address usage-based constructionalization, as its goal is not specifically centred on language innovation and large-scale formation of new patterns (cf. Traugott \& Trousdale 2013; Croft 2010). Rather, we are interested in the creative modification of a ritualised chunk of experience $[\mathrm{x}]$ as a cognitively/socially typical phenomenon as such. That is, we investigate the frequent online alteration of [x] independently from the subsequent propagation of a new conventionalised chunk $[y]$. With this premise, our focus is placed on two phenomena contributing to typical creative attempts of entrenchment inhibition: dynamic resonance (cf. Du Bois 2014) and social reciprocity. The latter in social interaction perhaps evolves from Gouldner (1960), a social psychologist. What interests us here is the potential this notion may have for explaining why interactants gravitate towards dynamic resonance. We will consider social reciprocity in the context of politeness theory. Reciprocity has been somewhat underplayed in studies of politeness, but its importance is acknowledged (e.g. Culpeper 2011; Leech 2014). Put simply, a speaker who produces an utterance in a particular context with a certain level of politeness puts the addressee under pressure to reciprocate in kind. The same also applies to impoliteness. However, as we will argue, reciprocity in (im)politeness has its limitations. Complete reciprocity makes for increasingly routinized, formulaic social routines, impinging on "systemic" (Du Bois 2014: 353) and automatised forms of resonance. This means that the power to express politeness or impoliteness is diminished. Consequently, interactants adopt creative strategies to disrupt reciprocation and inhibit ritual and entrenched patterns of interaction with the aim of implicating stronger politeness or impoliteness messages. 
This paper is structured as follows: section 2 introduces traditional claims and aims of diachronic usage-based research. Section 3 focuses on dialogic syntax and exploits the relationship between dialogic constructionalization and dynamic resonance. Section 4 is concerned with resonance and creativity intersecting with social reciprocity. Section 5 is the case study of this project, it provides a distinctive collexeme analysis (cf. Hilpert 2006) of the history of the dialogic construction [A: good morrow B - B: (good) morrow (A)] and its relationship with dynamic resonance and reciprocity. It will emerge that the increase of entrenchment inhibition of the chunk (by means of dynamic resonance and social non-reciprocity) will coincide with the falling into disuse of the same dialogic pattern.

\section{The usage-based framework: the primacy of frequency and automatisation}

Recent years in cognitive science have testified that function-specific chunks of verbalisation inherently affect how language is acquired, used and crucially the way the linguistic system as a whole changes through time. Repetition of formulaic utterances leads to subsequent conventionalization (Bybee 1998; Heine \& Kuteva 2007; Terkourafi 2015) of increasingly fixed patterns in individuals' memory. The latter then undergo further formal changes at the phonetic, semantic, grammatical and even pragmatic level. The combination of this model with an evolutionary approach to language change has led to a commonly endorsed paradigm that views language as a usage-based, complex adaptive system CAS (cf. Beckner et al. 2009). In CAS, “speakers' behavior is based on their past interactions, and current and past interactions together feed forward into future behavior" and "the structures of language emerge from interrelated patterns of experience, social interaction, and cognitive processes" (Ibid.: 2). Among the common assumptions of CAS, there is the probabilistic nature of linguistic behavior and the emergence of grammatical regularities from the interaction of agents in language use.

Token frequencies of linguistic constructions correlate with degree of entrenchment (Schmid 2000; Croft 2000; Gries 2010) viz. the degree of cognitive routinisation of linguistics structures and their likelihood to be stored in memory (cf. Langacker 1987, 2008). In corpus linguistics, this tendency is similarly captured with the so-called idiom principle, according to which "a language user has available to him or her a large number of semi-preconstructed phrases that constitute single choices, even though they might appear to be analysable into segments" (Sinclair 1991: 110). Cognitive linguists view the same phenomenon as the identification of a conventional symbolic unit (Langacker 1987; Croft \& Cruse 2004), viz. “a structure that a speaker has mastered quite thoroughly, to the extent that he can employ it in largely automatic fashion, without having to focus his attention 
specifically on its individual parts for their arrangement [...] he has no need to reflect on how to put it together" (Langacker 1987: 57).

In the same trend, usage-based cognitive studies have become interested in grammaticalization and semantic change occurring as a process of chunking (cf. Newell, 1990; Bybee, 2010), defined as "the underlying cognitive basis for morphosyntax and its hierarchical organization [...] of sequential experiences" which occurs mainly with repetition (Newell, 1990; Haiman 1994; Bybee 2003, 2010: 34). This is the process behind the formation and use of formulaic or prefabricated sequences of words such as take a break, break a habit, pick and choose (Bybee 2002, 2010), and automatised processing progressively allowing co-articulation and reduction as in the constructs I don't know/I'm going to grammaticalizing into more entrenched constructions $I$ dunno/I'm gonna. Chunking applies to morphemes, words, and larger formulaic patterns and is centred on semantic-pragmatic reanalyses due to newly acquired meaning in context. Chunking intersects with entrenchment and leads to progressive diminishing of the internal constituency of frequently used phrases. Newly formed chunks are processed holistically, which implies "that rather than accessing each unit separately and putting them in a construction, a whole sequence is accessed at once" (cf. Bybee, 2010, p. 52) . Continued access as a whole contributes to the weakening of the analyzability and/or compositionality of the chunk, that is the parts of the construction are increasingly less identifiable as independent grammatical and/or semantic unites. A famous example which illustrates this phenomenon is the so-called [WXDY?] construction:

What's this fly doing in my soup?

(cf. Fillmore \& Kay 1999).

The usual interpretation of What is $\mathrm{X}$ doing $\mathrm{Y}$ ? has to do with surprise at incongruity accompanied by an overt a hint of disapproval. The construction is now less semantically compositional as $\mathrm{Sp} / \mathrm{w}$ (Speaker/writer) is not literally interested in $\mathrm{p}$ as such, viz. what is the fly doing in the soup, but rather employs a [WXDY?] construction as a whole to express something else/more than the sum of its parts, namely, how did p happen? (1) above is just an example of diachronic reduction and compositionality and/or analysability of a linguistic pattern in favour of a newly holistic processing of the construction as a unit.

\subsection{Creativity as a mechanism of problem-solving in context}

The usage-based model reflects the emphasis that research in cognitive neuroscience has been given to 'creativity' as an experiential mechanism of computation aimed at learning/solving tasks and 
improving online performance and predictability (cf. McRae et al. 1997; Roland et al. 2012 on predictions about upcoming linguistic material). Crucially, the agenda in the study of cognitive architectures and artificial intelligence during the last 20 years has also had as a major goal the one of uncovering the mechanisms of experiential learning process and memory retrieval. Cognitive architectures such as ACT-R (Anderson et al. 2004), SOAR systems (i.e. Newell 1990) or Icarus (Langley et al. 2004) all account for felicitous problem-solving processing of previous chunks of experience. In new contextual conditions, previously entrenched structures of behaviour (i.e. impinging on implicit memory) or entrenched propositional beliefs (i.e. intersecting with declarative memory) implement a responsive performance during an online task.

Despite the outstanding results that this paradigm has led to, not as much attention as yet been paid to online decisions of inhibiting patterns of experience otherwise successful in accomplishing tasks, learning new behavioural cues and 'solving new problems'. This is not so surprising, as the very idea of inhibiting successful patterns of behaviour in situations where those are required may sound counter-intuitive. Yet, subtle variations of entrenched, prototypical patterns of conventionalised constructions is precisely what humans often do during speech events, even when the contextual or preparatory conditions (cf. Searle 1969) remain constant. Namely, aware of an entrenched chunk x [see you later], Sp/w may otherwise decide to utter $\mathrm{x}+/-\mathrm{y}$ [I'll see you again young man] (BNC G5E PS285) despite $\mathrm{x}$ having been repeatedly proved to be felicitous in the same contextual conditions.

\subsection{Creativity as a mechanism of entrenchment-inhibition in context}

Crucially, the large-scale formation of a prototype is undoubtedly triggered by a tendency towards schematicity, entrenchment. Yet, this fact does not necessarily lead to continuous reiteration of the same entrenched item during verbal experience. In light of this, this paper puts the accent on how innovation and subsequent formation of a prototypical pattern $\mathrm{x}$ does not necessarily correspond to the future increasing repetition of the schematic form $\mathrm{x}$ as such. Rather, it alternates with less predictable alterations of the type $x+/-y$, where $x$ corresponds to the prototype and $y$ its online variation.

Consider for instance the American English and British English frequent interjection [Oh my God], which is pragmatically used to convey surprise (either positive or negative) towards an unexpected event or information. In the spoken section of the BNC, [Oh my God] appears to be the prototypical token occurrence of the more schematic [Oh my x] construction. The prototype [Oh my God] occurs 277 times as a bounded construction (viz. ending with a punctuation mark) in the spoken 
section of the British National Corpus ${ }^{1}$ BNC (26.61 instances per million words) while the more schematic chunk [Oh my x] appears 378 times (36.31 instances pmw). From a general usage-based perspective we would be primarily interested in confirming that [Oh my God] functions here as the prototype of the more schematic [Oh my x] construction. While the collostructional attraction (viz. the statistical attraction between a lexeme and construction vs other constructional combinations) between collexeme God and the collostruct [Oh my x] indeed is extremely high (Fisher exact test, $\mathrm{p}$ $=7.239932 \times 10^{-218}$ ) and supports this conclusion (cf. Stefanowitch \& Gries 2003 on collostructional analysis), yet not much would be accounted for all the cases in which the two items do not co-occur as an entrenched chunk.

This is precisely what this study is concerned with, as we suggest that entrenchment is a cognitive process that during online speech production is in competition with a creative mechanism of inhibition. When the latter prevails, the chunk stops being processed in an automatised fashion as it normally 'should' - in favour of a new compositional structure:

A: do you suppose they got that name because [...] she was always...

B: Oh my Jesus, oh Willy, that is filthy!

BNC KDN 5273

Crucially, section 5 will provide evidence to suggest that large-scale phenomena of entrenchment inhibition need to be taken into account as a fundamental competing force of language conventionalization and increased schematicity.

\section{Dialogic syntax and resonance}

To operationalise a model addressing creativity as a dynamic mechanism of inhibition, it is necessary to rely on a framework that is specifically centred on the phenomenology of online interaction from a dialogic perspective. To elaborate, while usage-based analysis of constructs/constructions (cf. Traugott \& Trousdale 2013) is indeed based on real speech events, yet the very idea of construction traditionally refers to a pair of form and meaning uttered by a single speaker.

\footnotetext{
${ }^{1}$ http://bncweb.lancs.ac.uk/cgi-binbncXML/BNCquery.pl?theQuery=search\&urlTest=yes. Last accessed $09 / 03 / 17$.
} 
During the last few years, the notion of construction (i.e. Goldberg 1995; Fillmore \& Kay 1999) has been finally extended to a shared item involving both interlocutors during dialogs or other forms of online exchanges. This 'dialogic turn' has been formalised in the dialogic syntax model (cf. Du Bois 2014; see also Zima \& Brone 2015) and started to cast new light on the formation of new patterns as being inherently determined by dialogic exchanges. Namely, dialogic syntax (cf. Du Bois 2014; Du Bois \& Giora 2014) focuses on the dynamic relationship between dialogic speech events and constructional structure across utterances. This entails that the creative organisation of utterances is syntactically, phonetically, semantically and pragmatically affected by what has been said throughout the same speech event. In a similar fashion, the online employment of constructions occurs in dialogue as a joint project (cf. Clark 1996) or a co-action (cf. Reich 2011; Tantucci 2016) with the very idea of syntactical organisation being re-thought as a turn-taking driven mechanism.

Dialogic syntax relies on the so-called interactive alignment model (Pickering \& Garrod 2006), which is primarily interested "in a mechanistic psychology of dialogue" (cf. Dubois \& Zima 2014: 465) giving a special emphasis on the automatic alignment of constructions in discourse. Interlocutors are primed to re-use the linguistic input of immediately preceding utterances they have just processed. This explains the "high degree of repetition typical of interactive language use in comparison to written texts or monologues" (cf. Du Bois \& Zima 2014: 466). This phenomenon is widespread and extremely frequent in dialogue and reflects what in dialogic syntax is more broadly defined as resonance, viz. the "catalytic activation of affinities across utterances" (Du Bois 2014: 372). Resonance impinges on the degree of codified similarities (i.e. phonetic, semantic, syntactical and - we add - pragmatic) that may be observed throughout a dialogic speech event. Consider the pair of utterances below:

(3) That guy just handed the other a bag filled with booze.
B: No, the guy handed him a bag with books.

(Du Bois 2014: 467)

From (3) above, we can observe B resonating with A's utterance at different levels. At the syntactical level, this is an example of constructional analogy where the structure codified by A [DET guy X handed RECIPIENT a bag Y with NP] is echoed by B through a mirrored construct [DET guy X handed RECIPIENT a bag ¥ with NP]. At the lexical level we find a similar choice of words/phrases in the response from A to B: that $\longrightarrow$ the; guy = guy; handed = handed; a bag = a bag; filled with $\rightarrow$ with. This intersects with a phonetic similarity/correspondence across the two utterances, which is formalised through a similar choice of words and a close length of the utterance as a whole (the latter is directly connected to the constructional idiosyncrasy across the two assertions). From a 
pragmatic angle, the pair above is also interesting as it gives evidence of a type of overt disagreement in which the illocutionary force of B's utterance is boosted by structural similarity with A. In other words, a form of overt disagreement is achieved here by means of structural subtraction, viz. the echoing of a preceding proposition $\mathrm{p}$ where an element $\mathrm{x}$ [booze] is markedly replaced with y [books]. This is an instance of what in section 5.7 will be identified as contrary intensifying parallelism.

\subsection{Dynamic Resonance, re-composition and entrenchment inhibition}

Resonance may be systemic, viz. based on stable properties of the language that are available to all members of the community as in the repetition of a formula in greetings [A: good morning B: good morning]. Interestingly, resonance also often occur as a creative process of alteration, as in (3) above. In this latter cases it is referred to as dynamic, viz. being "constructed on the fly in ways that may be comprehensible only to those who were present in the dialogic moment" (cf. Du Bois 2014: 353). The present discussion, is primarily concerned with cases of resonance occurring dynamically, as we are specifically interested in the creative activation of new constructions through dialogic speech events. Dynamic resonance occurs formally through parallelism and/or analogy (i.e. Fischer 2008; Gentner and Christie 2010) and pragmatically, i.e. by boosting or altering of the illocutionary force a preceding utterance. Consider the following exchange where B resonates with A's utterance yet transforming the illocutionary force of the chunk, from a greeting to an assertion:

\section{(4) A: Alright Martin I'll see you later.}

B: I'll see you later anyway.

I'll...

A: Okay yeah.

BNC HMD 1459

In (4) above, A employs a conventionalised formula to perform a greeting, I'll see you later. Interestingly, B's resonance is built on a parallelism with A's proposition I'll see you later with the formal addition of the discourse marker anyway. As a result, B creatively intervenes on the conventional construction I'll see you later as s/he makes a new assertion aimed at re-assuring both interlocutors that they are actually going to be meet each other later. This form of resonance is a case of entrenchment inhibition in that B newly re-analyses the construction as a more compositional chunk. Put simply, the formula I'll see you later is not used by B as a greeting (i.e. in the way good bye would be), but it rather conveys its propositional meaning, paraphrasable as it is a fact that we will see each other later. This pragmatic 'effort' can be made to convey specific politeness or 
impoliteness implicatures: in this case B could be construed as implicating polite reassurance. Section 4.1 will elaborate on how such (im)politeness implicatures might be generated by non-reciprocal responses.

This type of online alteration of a conventionalised construction is achieved by means of recomposition, viz. the semantic re-discovery of the internal constituency of a conventionalised construction $\mathrm{x}$ in the form of $\mathrm{x}+/-\mathrm{y}, \mathrm{x}$ being the constructional prototype I'll see you later and $\mathrm{y}$ its online variation $\underline{a_{n y w a y}}$. From the corpus-based survey in section 5 it will emerge that online creativity occurs dialogically precisely through the mapping of similar structures, sounds or pragmatic moves from one interlocutor to another. It will made the case of dynamic resonance and spontaneous variation across utterances being an important variable counterbalancing large scale tendencies of chunking and entrenchment. Data from the present survey are to suggest that schematicity and ultimately, grammaticalization seem to be in competition with creative attempts of online inhibition of prototypical patters of usage. The large-scale corpus-based analysis in section 5 makes a pitch for entrenchment inhibition and dynamic resonance as variables which may crucially complement most usage-based approaches to semantic change and grammaticalization. Further quantitative surveys focusing on entrenchment inhibition as a competing factor of conventionalization will shed new light on a number of historical phenomena that the usage-based model is presently missing. Among those:

- Observable tendencies of falling into disuse of well-established constructions.

- New qualitative and quantitative methods to explain why some forms have a 'longer-lasting' life than others.

- The degree to which entrenchment inhibition constitutes a variable that counterbalances tendencies towards to conventionalization and grammaticalization.

- Whether some linguistic functions (or dialogic exchanges) are more likely to intersect with online attempts of entrenchment inhibition than others.

- The nature of cognitive/social factors triggering attempts of dynamic resonance and entrenchment inhibition.

4. Resonance at the socio-pragmatic level: Reciprocity, creativity and change in (im)politeness exchanges

\footnotetext{
${ }^{2}$ In the rest of the paper we will embolden parallel items across dialogic pairs, while we will underline marked elements of online variation.
} 
Social reciprocity figures as the so-called "Golden Rule" in many religions (e.g. "Do unto others as you would have them do unto you", Luke 6.31). It is an important social norm, discussed in social psychology and sociology in particular. For Malinowski (1932: 55), rights and obligations are part of social machinery and "realised in the equivalent arrangment of reciprocal services". Gouldner (1960: 171), in an important early statement, points out that behind reciprocity is "a generalized moral norm [...] which defines certain actions and obligations as repayments for benefits received" (1960: 170). Within linguistics, or more precisely sociopragmatics, one might have expected linguistic politeness studies to have been much concerned with reciprocity - a polite utterance being met with a polite response. However, it is only recently that politeness studies have begun to pay reciprocity some attention.

Politeness is akin to a social payment (see Watts 2003: 115, for an articulation of the idea that politeness is like money). Reciprocity appears to be present in Brown and Levinson's (1987) classic framework. Here, it is argued that it is of "mutual interest" (1987: 60) for interactants to cooperate by supporting each other's face: “[i]n general, people cooperate (and assume each other's cooperation) in maintaining face, such cooperation being based on the mutual vulnerability of face" (1987: 61) (see also Goffman 1967: 29). An insult would 'resonate' leading to a reciprocal counter-insult, and thus the speaker has a vested interest in maintaining the hearer's face, since this will enhance the probability of reciprocal supportive facework. However, mutual interest is not the same as reciprocity, though it may be a factor that promotes reciprocal behaviours. Empirical work has established that reciprocity - the moral obligation to meet like with like - can trump self-interest. Fehr et al.'s (2002) study, for example, demonstrated that people are willing to undertake actions to their own detriment in order to maintain reciprocity. More recently, reciprocity has been accorded more attention in politeness studies. Spencer-Oatey (2005: 100), for example, proposed various "sociality rights”, one of which concerns "equity" and includes reciprocity, "the belief that costs and benefits should be 'fair' and kept roughly in balance". Culpeper (2011: 36-41, 203-207), noting the general neglect of reciprocity in politeness studies, shows how reciprocity plays an important role not only in prosocial actions but also antisocial ones; in other words, in impoliteness as well as politeness. Just as reciprocal polite thank yous, sometimes repeating themselves over several exchanges, are not uncommon in British culture, so reciprocal impolite exchanges (e.g. an insult followed by an insult) are also not uncommon.

\subsection{The surplus approach}

Some approaches to politeness (e.g. Kasper 1990; Watts 2003) argue for a 'surplus' approach, the idea that the label politeness should be restricted to cases where there is an unexpected surplus of 
politeness behaviour, given the context. These would be cases where an entrenched pattern of behaviour is dynamically inhibited in favour of 'more' meaning in context. Let us see how reciprocity interfaces with this. In order to discuss the surplus approach, we need to introduce the notion of "politic behaviour", which encompasses the mundane formulaic politeness work of interaction. Watts (1989, 2003) defines politic behaviour as: "[1]inguistic behaviour which is perceived to be appropriate to the social constraints of the ongoing interaction, i.e. as non-salient, should be called politic behaviour" (Watts 2003: 19). He supplies the following examples (emboldening is as per the original where they indicate politeness formulae; however, we have also emboldended "Would you like ..." as a polite offer formula):

(5) A: Would you like some more coffee?

B: Yes, please.

(6) A: Hello, Mr. Smith. How are you?

B: Hello David. Fine thanks. How are you?

(Watts 2003: 186, emphasis as original)

Although there is no mention of it by Watts, both of these examples also illustrate reciprocity on the part of the second speaker: a polite first move matched by a similarly polite second move. Interestingly, the reciprocal exchange in (6) also intersects with systemic resonance, in the form of the entrenched pair [A: Hello B, how are you?] [B: Hello A, REPLY, how are you?]

For Watts, politeness, as opposed to mere politic behaviour as discussed above, is positively marked behaviour: "[1]inguistic behaviour perceived to go beyond what is expectable, i.e. salient behaviour, should be called polite or impolite depending on whether the behaviour itself tends towards the negative or positive end of the spectrum of politeness" (2003: 19). By way of illustration, let us re-work Watts's second example accordingly:

(7) A: Hello, Mr. Smith. It's great to see you. We missed you. How are you?

B: Hello David. I'm fine thanks. It's great to see you too. How are you?

Both these utterances go beyond what is expected. Moreover, speaker maintains reciprocity by matching the politeness level of A's utterance. But it is easy to see how this need not be the case. Consider this re-working of the first example (non-reciprocal elements are underlined):

(8) A: Would you like some more coffee? 
B: Yes,_please, that's very kind, coffee would be wonderful.

B's response does politeness, in the sense that Watts intends, but it is not reciprocal: it does more than repay the politeness (politic behaviour) articulated in the first utterance. It has the potential, context permitting, to be evaluated as more polite than a straightforwardly reciprocal response. And of course the converse is entirely possible:
A: Would you like some more coffee?
B: $\quad$ Yes.

Here, B's response does less than A's politic behaviour; it is not reciprocal. It has the potential, context permitting, to be evaluated as impolite.

\subsection{Reciprocity and language change}

How does non-reciprocity trigger an (im)politeness implicature? There are several ways of explaining this within pragmatic theory. One is with reference to Levinson's (2000) M-Principle. This principle has a speaker's maxim and a recipient's corollary. The Speaker's maxim states: “indicate an abnormal, non-stereotypical situation by using marked expressions that contrast with those you would use to describe the corresponding normal, stereotypical situation" (2000: 136). The recipient's corollary states: "What is said in an abnormal way indicates an abnormal situation, or marked messages indicate marked situations [...]" (2000: 136). Levinson (2000) did not have social reciprocity across exchanges in mind (though he does apply the M-Principle to speaker repetitions), but we see no reason why it does not apply to the kinds of examples we have been discussing here. Reciprocity is, as we have argued, a social norm. Therefore, departure from reciprocity is an abnormal situation, and, and moreover, linguistically marked by more prolix or periphrastic and less frequent or neutral forms, or by an absence of expected linguistic material. Marked forms "suggest some additional meaning or connotation absent from the corresponding unmarked forms" (Levinson 2000: in his discussion of 137). In his discussion of repetition, Levinson (2000: 148) notes that a repetition "should implicate in narrowing to, for example, an extreme" variant of the subset of denoted entities that would flow from the unmarked form (e.g. long long would implicate not just long, but very long). And so it is with (im)politeness implicatures: non-reciprocity triggers politeness or impoliteness implicatures that go beyond unmarked politic behaviour.

Reciprocity is not a force for language change. Gouldner notes that "social system stability [...] presumably depends in part on the mutually contingent exchange of gratifications, that is, on 
reciprocity as exchange" (1960: 168). Reciprocity across exchanges entails stability: the echoing, at some level, of the previous speaker. This kind of reciprocity does involve a kind of creativity. Creating a pattern by echoing the previous speaker is referred to by Carter (2004) as "pattern forming" creativity in his work on creativity in conversation. But note that this is this kind of patterning involves little cognitive disruption, and is not typical of discussions of creativity. The important point for us is that straightforward reciprocity makes for routinization, entrenchment and automatization, thus directly impinging on systemic resonance. It does not enable one to move beyond politic behaviour and implicate stronger messages of politeness or impoliteness. More disruptive, and more typically creative, cases are non-reciprocal cases like examples (8) and (9). These would fall under Carter's other type of creativity, "pattern re-forming" creativity, which in our account occurs formally as a dynamic form of resonance. Carter largely discusses this in relation to within-utterance cases that break a linguistic pattern, such as "out of the frying-pan into the deep freeze" (2004: 95) instead of the more conventional "out of the frying-pan into the fire". However, there is an obvious sense in which across an exchange one can break the pattern set up by a previous speaker by means of entrenchment inhibition and re-composition, which is precisely what happens in examples (8) and (9). People creatively depart from the reciprocity norm of systemic pairs, thereby inviting the interpretation of politeness or impoliteness as opposed to mere unmarked politic behaviour or appropriateness. The former often intersects with dynamic attempts of resonance, while the latter instantiates as a systemic and routinised one.

\section{Dynamic resonance as a form of entrenchment inhibition: The case of good morrow}

\subsection{The dialogic constructionalization of [A: good morrow B - B: (good) morrow} (A)]

This section provides corpus-illustrated (cf. Tummers et al., 2005: 235) data focusing on the process of constructionalization of the dialogic pair [A: good morrow B - B: good morrow (A)] from the 15th until the 18th century. The term 'corpus-illustrated' refers to a technique adopted in historical linguistics to illustrate new stages of semantic or grammatical reanalysis in a diachronic corpus (influential accounts based on corpus-illustrated techniques can be found in Traugott 1999, 2010, 2012; Bybee, Perkins, \& Pagliuca, 1994; Hopper \& Traugott, 2003; and others). The main purpose of this introductory study is to give preliminary evidence about the process of entrenchment leading 
to the increased prototypicality (i.e. Langacker 2008: 34; Evans 2007: 175) of [A: good morrow B B: good morrow (A)].

Our annotated dataset draws from the EEBO (Early English Books Online) v3, which contains a total of 1,202,214,511 words. The texts types include literature, philosophy, politics, religion, geography, science and all other areas of human endeavour from the first book printed in English in 1475 through to 1799 . We extracted all 1613 occurrences of good as collocate of morrow (+/5 span) in texts from the 15 th up to the 17 th century; these occurrences were then manually checked to eliminate those where good is not related to morrow - e.g. to morrow. After the cleaning process, the final data sample was composed of 1557 occurrences.

To start with, in early stages of constructional change (1450-1500), good morrow occurs in non-dialogic ditransitive constructions [NP GIVE NP (the) good morrow]:

(10) Gafe him the good morrow.

EBO A68341 1477

(11) Noble lord and lady, god give you good morrow.

EBO A10638 1481

During the 1500, good morrow starts to be uttered 'performatively' (i.e. Verstraete 2001: 1517; Nuyts 2012: 58) in a dialogic dative form [Good morrow to NP] with a shift from a syntactic to a speaking subject (i.e. Benveniste 1958; Langacker 2008). The construction is now more inter(-subjectified) as it indexes to a greater degree of Sp/w's attention on the Ad/r's self-image (i.e. Traugott and Dasher 2002; Traugott 2012), as the chunk is uttered to directly greet an $\mathrm{Ad} / \mathrm{r}$ rather than sharing information.

Notably, the chunk is now less analysable, as the syntactic subject together with the main verb are dropped. It is also less compositional, with the dative construction lacking an agent and with no more reference to the action determining the transmission of the good morrow to the beneficiary.

(12) A: Good morrow to your Majesty.

B: Good morrow to my loving Cousin of Guise.

EBO A10638 1481

To elaborate, at this stage we start having recurrent cases of systemic resonance, in which $\mathrm{B}$ reciprocates syntactically and pragmatically the same function used by A. These are the earliest instances of good morrow being systemically codified as a part of a dialogic construction. 
During the 16th century, good morrow starts to be used as a greeting in a dialogic vocative chunk [A: good morrow B - B: good morrow A]. Here we can observe a higher degree of chunking and syntactic/phonetic reduction, with the drop of the preposition to. The latter determines a comparatively lower degree of analysability as the beneficiary is no longer marked. The compositionality of the construction has also decreased with the sum of the two elements [ $g o o d$ morrow $]+[\mathrm{NP}]$ no more literally expressing that an agent is transmitting a greeting to a beneficiary:

\section{(13) A: Good morrow Ned. \\ B: Good morrow sweet Hal.}

EBO A11966 1598

The constructional shift from (10) to (13) moves in the direction of a greeting that is processed by both interlocutors as an increasingly entrenched, automatised dialogic construction. This becomes even more evident in a further phase of constructionalization, with the dropping of the vocative from B's utterance [A: good morrow B - B: good morrow (A)]:

(14) A: Good morrow brother.

B: Good morrow.

EBO A14660 1616

Finally, during the 17th century, there will be the drop of good in B's response corresponding to the highest degree of entrenched processing of the greeting:
(15) A: Good morrow Ladies.
B: Morrow my good Madam.

EBO A00967 1640

\subsection{The identification of a prototype: A diachronically informed approach}

This brief illustrated excursus about the constructionalization of the chunk [A: good morrow B - B: good morrow (A)] is needed for a diachronically informed definition of a prototype. The latter is acknowledged as the cognitive most salient exemplar among the members of a category (cf. Rosch \& Mervis 1975; Cruse 2006). Gilquin (2006) proposes two features that are often assumed to be indicative of linguistic prototypicality: salience (as the relative accessibility of different senses of a 
polysemous word in a zero-context sentence production task) and corpus-frequency (see also Gries 2003 for a synchronic usage-based method for the identification of prototypes in a corpus).

In the present study, a prototype is addressed as a diachronically informed notion. Effects of asymmetric priming, (i.e. from space to time, but not vice versa, Boroditsky 2000), are hypothesized to be plausible linguistic replicating mechanisms leading to directionality in semantic change and grammaticalization (i.e. Jäger and Rosenbach 2008; Traugott \& Trousdale 2013). Taking the cue from unidirectional accounts of semantic and constructional change (i.e. Traugott \& Dasher 2002), we identified a prototype as a form $\mathrm{F}$ with a specific function or illocutionary force $\mathrm{I}$ (in this case a greeting) at a moment/period in time $\mathrm{t}$. $\mathrm{F}$ at $\mathrm{t}$ displays the highest frequency among the members that originated from the same less entrenched source S (i.e. the pair in (14) in relation to good morrow in (10) above). In the (abstract) scenario in which two constructions from the same cline of change displayed the same frequency at $\mathrm{t}$, the comparatively more entrenched one (viz. less analysable and compositional) would be identified as the prototype. Finally, still with the aim of setting an operational and verifiable framework of analysis, we also identified as non-prototypical all those forms that despite being part of a same cline of change, yet do not convey the same function I that we expect for F (i.e. all forms consistently including good morrow yet used to make an assertion rather than a greeting). The intersection of the five corpus-based criteria of annotation, Form F, Illocutionary force or function I, Source S, frequency and entrenchment is summarised in (16):

@ t $x$ :
a. PROTOTYPE:
$\mathrm{F} x, \mathrm{I} x, \mathrm{~S} x$ [+ frequency] [+ entrenchment]
b. PERIPHERAL:
$\mathrm{F} x, \mathrm{I} y, \mathrm{~S} x$ [ \pm frequency] [ \pm entrenchment]
c. PERIPHERAL:
$\mathrm{F} y, \mathrm{I} y, \mathrm{~S} x$ [ \pm frequency] [ \pm entrenchment]
d. PERIPHERAL:
Fy, Ix, Sx [- frequency] [+ entrenchment]
e. PERIPHERAL:
$\mathrm{F} y, \mathrm{I} x, \mathrm{~S} x$ [= frequency] [- entrenchment]
f. NO-MEMBER:
$\mathrm{F}, \mathrm{I} x, \mathrm{~S} y$

According to the annotation criteria above, at (@) a specific point in time/time-span (tx), a PROTOTYPE is the form Fx originating from a source $\mathrm{S} x$, conveying a specific function or illocutionary force $\mathrm{I} x$, displaying the highest degree of frequency and entrenchment. PERIPHERAL members $(16 b, c)$ originating from the same source $S x$ have different functions I $y$. A different form Fy (16d) with a function $\mathrm{I} x$ that is the most entrenched among the members of $\mathrm{S} x$, is not a prototype if still less frequent than Fx. Similarly, if a form Fy (16e) originating from Sx conveys the same function I $x$ and is as frequent as Fx, it cannot be considered a prototype if less entrenched than Fx. 
Finally, all constructions (16f) originating from a different source than Sx are not to be considered as members of that category.

\subsection{A corpus-based analysis of entrenchment and dynamic resonance}

Our corpus analysis has three main aims:

1) To investigate the degree of entrenchment of the dialogic pair [A: good morrow B - B: (good) morrow (A)] leading to the formation of a prototype on a quantitative level.

2) To shed light on the subsequent relationship between entrenchment and prototype effects on the basis of quantifiable features, namely collostructional strength (Stefanowitsch \& Gries 2003) and collocations.

3) To investigate and quantify the presence of dynamic resonance as a force of entrenchment inhibition.

In order to undertake the analysis of prototypicality we first needed to define a methodology for the quantitative identification and analysis of our prototype. We queried the corpus to collect those occurrences where good morrow collocates with morrow from the 15th up to the 18th century using a -/+ 8 span. This span was chosen - instead of the "standard" +/-5 (cf. Seretan and Wehrli 2007) due to the types of texts that compose the corpus: these texts are heterogeneous and range from letters to play-scripts, and often contain parts of text that can be considered as "meta-text" such as i) the names of the character that utters the lines or ii) stage indications.

As suggested by the collocations results, there seems to be a strong link between good morrow and its collocate morrow, with a LogRatio of 9.305 (cf. Casella \& Berger 2001). Crucially, the remaining collocates are names of characters (as mentioned earlier, the corpus is composed by i.a. theatrical scripts) ${ }^{3}$. Based on the annotation criteria from section 5.2, occurrences collected from the collocation database were then manually checked for false-positives (e.g. the collocate morrow as part of the word to morrow).

\subsection{Prototypical pairs vs dynamic resonance}

The identification of prototypicality and dynamic resonance was operationalized based on the criteria given in (16), and is illustrated by examples (17-25) below. Double-checking (by all three authors)

\footnotetext{
${ }^{3}$ The first collocate, $t^{\prime} y e$, is the abbreviated form of to ye (to you), which is elliptical of good morrow to you.
} 
was adopted to ensure the lowest possible level of errors. The exchanges in (17-19) exemplify the criteria for the identification of the prototype in the form of [A: good morrow B - B: good morrow A]. These types of occurrences have been marked with " 1 " in the spreadsheet for prototypicality and with " 0 " in the spreadsheet for dynamic resonance. Exchanges (20-21) are examples of systemic resonance intersecting with phonetic reduction and further schematicity in the form of [A: good morrow B B: morrow]. Here, the second good morrow has been reduced to morrow and acquired a higher degree of schematicity through ellipsis. These types of occurrences also have been marked with " 1 " for prototypicality and with " 0 " for dynamic resonance.

(17) A: Good morrow Captain Bessus.

B: Good morrow Sir.

EEBO A06207 1610_1619

(18) A: Good morrow neighbour Baptista.

B: Good morrow neighbour Gremio [...]

EEBO A11954 1620_1629

(19) A: Good morrow Uncle Pandarus.

B: Good morrow Cozen Cressid: what do you talk of?

EEBO A11954 1620_1629

(20) A: Good morrow most dear, and worthy to be most wise, how does my mistress?

B: $\quad$ Morrow sweet servant, you glister, pree thee let's see that stone.

EEBO A07065 1600_1609

(21) A: Good morrow my Lord.

B: $\quad$ Morrow good brother.

EEBO A13840 1610_1619

In example (22) on the other hand, effects of dynamic resonance are at play: the $\mathrm{Ad} / \mathrm{r}$ re-composes the salute by inhibiting its conventionalized meaning and turning it into a question (i.e. Ix $\longrightarrow$ Iy, see section 5.2) and adding the added comment It is now my bedtime (elements of dynamic resonance are underlined):

(22) A: Good morrow sir.

B: $\quad$ Morrow? [I]t is now my bed time. 
(23-25) below are further examples where the Ad/r inhibits the entrenchment of the pair by directly engaging with the prototype through semantic re-composition. The latter ( $\mathrm{F} y, \mathrm{I} y, \mathrm{~S} x$ ) have been marked with " 1 " for dynamic resonance, and with " 0 " for prototypicality:

(23) A: Good morrow wife, how do you this morning?

B: $\quad$ As many evil morrows may thou have, as I have words to speak, or tears to vent

EEBO A13461 1630_1639

(24) A: Good morrow, Ferdinand.

B: Good morrow to thy death: draw, Pembrook, draw, The ground thou treadst upon, must be thy grave .

EEBO A03404 1600_1609

(25) A: Good morrow my good Lord Chamberlain.

B: $\quad$ Many good morrows to my good Lord of Sussex.

EEBO A03208 1600_1609

We will further discuss examples such as these in section 5.7. There, we will propose a social mechanism, social reciprocity, that underpins such pairs, and explain how such examples as (22-25), displaying dynamic resonance or non-reciprocality, are a means of generating polite or impolite implicatures.

\subsection{Formation and decline of a prototype: A distinctive collexeme account}

At this point we aimed to calculate the strength of attraction between good morrow and the prototypical pattern [A: good morrow B - B: (good) morrow (A)] and quantify the role that entrenchment plays in the use of the construction. This has been achieved through a distinctive collexeme analysis (Hilpert 2006; Gries \& Hilpert 2008). This method allows for the calculation of the collostructional strength of an item in a construction and can be used for comparisons across diachronic corpora. It involves the creation of a contingency table where each row represents a different time-span, $\mathrm{t} x$, ty (in our case, a decade), and the two columns contain the occurrences of the lexeme $(\mathrm{L})$ in the construction $(\mathrm{C})$ (colum " $\mathrm{L}+\mathrm{C}$ ") and the occurrences of the construction without the lexeme (column "C-L"): 


\begin{tabular}{|c|c|c|c|}
\hline & $\mathrm{L}+\mathrm{C}$ & L-C & Totals \\
\hline 1470 & 0 & 6 & 6 \\
\hline 1480 & 0 & 4 & 4 \\
\hline 1490 & 0 & 3 & 3 \\
\hline 1500 & 0 & 0 & 0 \\
\hline 1510 & 0 & 2 & 2 \\
\hline 1520 & 0 & 3 & 3 \\
\hline 1530 & 0 & 6 & 6 \\
\hline 1540 & 0 & 18 & 18 \\
\hline 1550 & 0 & 6 & 6 \\
\hline 1560 & 0 & 18 & 18 \\
\hline 1570 & 0 & 29 & 29 \\
\hline 1580 & 0 & 40 & 40 \\
\hline 1590 & 8 & 88 & 96 \\
\hline 1600 & 21 & 177 & 198 \\
\hline 1610 & 7 & 145 & 152 \\
\hline 1620 & 11 & 141 & 152 \\
\hline 1630 & 3 & 109 & 112 \\
\hline 1640 & 3 & 69 & 72 \\
\hline 1650 & 3 & 129 & 132 \\
\hline 1660 & 8 & 125 & 133 \\
\hline 1670 & 5 & 144 & 149 \\
\hline 1680 & 8 & 145 & 153 \\
\hline 1690 & 11 & 142 & 153 \\
\hline 1700 & 5 & 30 & 35 \\
\hline Total & 93 & 1579 & 1672 \\
\hline
\end{tabular}

Table 1.

Input for a distinctive collexeme analysis of a lexeme $\mathrm{L}$ in a constructions $\mathrm{C}$ in the decades from 1470 to 1700 
The adoption of distinctive collexeme analysis has allowed us to deal with the size-disparity of the sub-corpora, as the data available for each decade ranges from slightly more than 1,000 tokens up to more than 168 million tokens. For the calculation of the collostructional strength we used the presence of prototypicality as input for the lexeme, therefore obtaining a measure of how much good morrow attracts the prototypical construction [A: good morrow B - B: (good) morrow (A)] as opposed to any other construction. Hence the annotation was used as input for a distinctive collexeme analysis for good morrow appearing in a prototypical greeting, following the structure in table 1. The results (fig. 1) show whether good morrow attracts (Prototype, triangle line) or rejects the prototype (NotPrototype, dot line).

Prototype vs. Not-Prototype

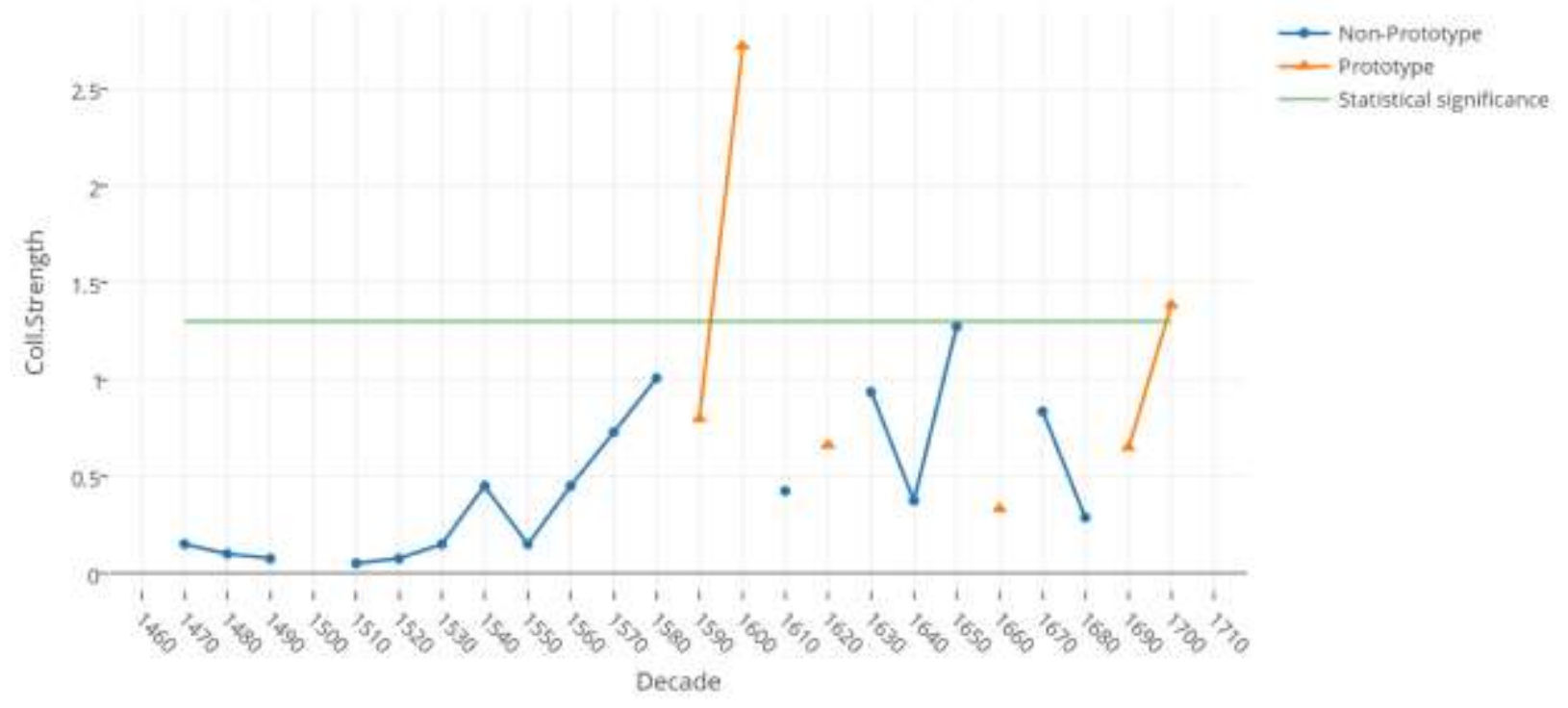

Figure 1 distinctive collexeme analysis of good morrow as part of the prototype [A: good morrow B - B: (good) morrow (A)]

The $\mathrm{x}$ axis displays each decade of the period we considered, while the $\mathrm{y}$ axis indicates the collostructional strength of the attraction between good morrow and a prototypical greeting [A: good morrow B - B: (good) morrow (A)] (triangle line) being in competition with good morrow being attracted to anything else (dot-line). It appears that prototypicality is significantly linked to good morrow in the decades 1600 and 1700. It is important to note that the results for these two decades are the only statistically significant results (statistical significance is fixed for collostructional strength at 1.3, indicated in the graph by the horizontal line). The absence of a link between the Non-Prototype line and the Prototype line is due to the fact that they represent two antagonistic variables: the collostructional analysis script output only signals which one (among the two variables) is preferred, 
and therefore when the Prototype is the preferred construction, no collostructional strength is given for the Non-Prototype one - and viceversa.

Crucially, significant degrees of collostructional strength show that 1600 is the decade where good morrow acquired the highest degree attraction to the prototype (the greeting was formed), which then decreased in 1700. In the next section we discuss the presence of dynamic resonance across decades and how it intersects with prototypicality.

\subsection{Dynamic resonance and entrenchment inhibition}

At this stage, we set out to investigate the presence of dynamic resonance in relation to the history of the prototype. In order to do so, we queried the sub-corpora for the search string morrow, and subsequently collected all the occurrences where good is a collocate at a $+/-5$ span. This time the "standard" span was chosen as the occurrences we are looking for are the ones where good is a direct modifier of morrow. The occurrences were then checked and annotated for the presence of dynamic resonance. Fig. 2 contains the data normalised to per-milion-words (pmw) and plotted by decade:

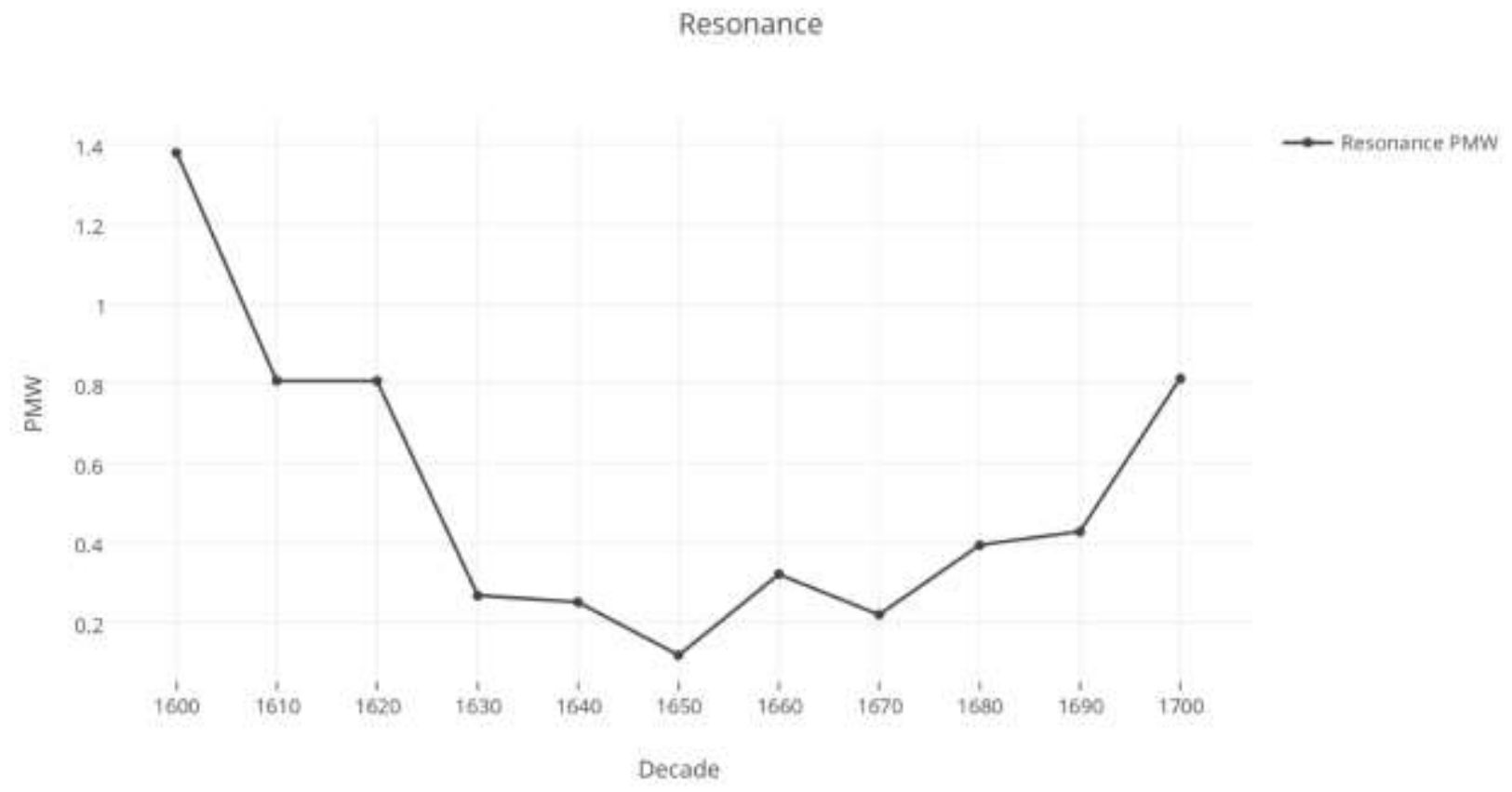

Figure 2: Dynamic resonance pmw

After a peak in 1600 (corresponding to the moment where the prototype acquired the highest degree of colloctructional strength), the construction was first characterized by a harp decrease in dynamic 
resonance. What is however more striking is a new increase starting from 1650, showing that individuals newly started to engage with the codified prototype in a creative way, viz. by means of re-composition and creative reciprocal exchanges. Despite the quantity of data available for the decades following 1700 declining in the corpus, yet the presence of good morrow is no more attested after 1700. We therefore tested the presence of the good morrow in the Corpus of English Dialogues (CED, a 1,183,690 tokens corpus composed of digitised Early Modern English spoken interactions) where good morrow only appears once in the decades following 1700. From our data, we may conclude that good morrow fell into disuse around the beginning of the 18th century.

Most intriguingly, the plot of the two graphs suggests that, after the established formation of the entrenched, prototypical pattern [A: good morrow B - B: (good) morrow (A)] in 1600, around 1650 individuals progressively started to 're-compose' it and creatively engaging with it. At a glance, it may sound paradoxical that prototypicality progressively ensued dynamic resonance and nonreciprocity. After all, increased entrenchment, schematicity and conventionalization should lead to a decrease of online alteration, with individuals being expected to reiterate those constructions that are more entrenched. Put simply, variations (and therefore the effects of dynamic resonance) should be cognitively discouraged by the increasing automatization and loss of internal constituency of the dialogic chunk. Yet, our data suggest a significant interplay between dynamic resonance and entrenchment inhibition. The two seem to converge in the cognitive attempt to re-compose an entrenched pattern of behaviour through a creative engagement with its parts. Finally, it is important to note that falling into disuse of good morrow after 1700 coincides with the progressive increase of dynamic resonance from 1650 up to the same period ${ }^{4}$.

\subsection{Non-reciprocity, creativity and (im-)politeness as a trigger of entrenchment inhibition}

As we have already demonstrated, dynamic resonance peaked around 1600 with the formation of the prototype of good morrow (that greeting being met by the same greeting). Subsequently, there was first a decrease of dynamic resonance. Yet, around 1650 dynamic resonance newly increased exponentially as individuals started to engage with the entrenched prototype in a creative way. In this section, we identify the specific kinds of dynamic resonance being represented in the Early modern texts, specifically in terms of reciprocity and creative (im)politeness.

With regard to creatively generating politeness, three types emerged in the data:

\footnotetext{
${ }^{4}$ Creative attempts of entrenchment inhibition may reasonably lead to diachronic propagation of negative entrenchment (cf. Stefanowitsch 2008), viz. the entrenched ability to suppress a construction in favour of a more conventional one.
} 
Implied reciprocation

(26) A: Good Morrow Neighbour, Why in such haste?

B: Not in such haste as not to return your good Morrow.

EEBO A81414 1690_1699

Matching parallelism

(27) A: Good morrow to my good Mistress Mathea.

B: As good a morrow, to the morrow giver.

EBO A02800 1610_1619

Escalation

(28) A: Good morrow gentle Sir.

B: $\quad$ The like good day, with a thousand happy years betide your worthy self.

A: $\quad$ Sir, I wish no less to you, and also am glad of your prosperous return out of the country.

EEBO A08653 1610_1619

In none of these examples does the second speaker simply reciprocate. Instead, they produce a marked version of the first speaker's utterance. In doing so, they implicate, via the M-Principle, politeness rather than mere formulaic politic behaviour. Let us examine the ways in which they are marked.

In the first, B does not reciprocate the greeting in the second part of the exchange nor does so in subsequent turns. Instead, (s)he implicates good morrow, via the Maxim of Quantity (Grice 1975), by stating that a condition that would prevent a good morrow does not apply. In the second example, B maintains some key structural elements of the first [ $\operatorname{good}(\mathrm{a})$ morrow to A], thereby creating a parallel structure. The elliptical statement [I wish] as good a morrow implicates, via the Maxim of Relation (Grice 1975), an equal good morrow to the previous speaker. The third example involves reformulation. In the second part of the greeting, B's the like clearly reciprocates, and good day matches good morrow, but then escalates the greeting in the remainder of the utterance: with a thousand happy years betide your worthy self. A's third part employs exactly the same strategy.

With regard to creatively generating impoliteness, three following types emerged in the data:

Contrary intensifying parallelism 
A: So good morrow to your Lordship.

B: Now. Good devil to your rogueship. No man 's safe I 'll have a Cannon planted in my chamber $[\ldots]$

EEBO A07251 1630_1639

Withholding

(30)

A: Good morrow to your Lordship; what does your Lordship mean?

B: What did you mean, Rascal, to make me mad, horn mad, with this counterfeiting Blindness?

EEBO A54956 1690_1699

Rejection

(31)
A: Good morrow Monsieur Miramont.
B: $\quad$ O sweet Sir, Keep your good morrow to cool your Worships pottage [...]

EEBO A54956 1690_1699

In the first, the response maintains some key structural elements from the first [ good NP to your Bship), but substitutes the original positive words, good and Lord, for negative, devil and rogue. The response in the second example simply ignore the good morrow in the first part. In the third example, B's response goes on record in rejecting the good morrow.

\section{Conclusions}

Entrenchment does not necessarily correspond to predictable behaviour. Contrary to what would be expected from a general usage-based perspective, the formation of the prototypical dialogic construction [A: good morrow B - B: (good) morrow (A)] in 1600 ensued a large scale tendency of semantic re-composition and dynamic resonance. We defined this process as entrenchment inhibition, viz. the creative manipulation of a schematic/entrenched chunk of experience and its internal constituency. We have proposed that the key factor underlying dynamic resonance and entrenchment inhibition is social reciprocity. The latter is an important social norm that puts pressure upon conversational participants to reciprocate in kind. Although this is keenly relevant to the workings of (im)politeness, it has all but been ignored in the literature. We explained how reciprocity in fact underpins the 'surplus' approach to politeness (e.g. Kasper 1990; Watts 2003). A merely formulaic, 
politic utterance pressurises the addressee to return the same. However, the addressee also has the possibility of not simply reciprocating but doing more, thereby implying a greater level of politeness (hence, the 'surplus' approach). We argued that the same also applies to impoliteness. We suggested that these additional (im)politeness implicatures could be explained in terms of Levinson's (2000) M-Principle, and briefly noted that non-reciprocal responses involve creativity. With respect to good morrow, in section 5.7, we revealed how after 1630-1650 more creative non-reciprocal pairs emerged, and highlighted the specific types. We propose this paper as a 'manifesto' of a qualitative and quantitative operationalization of large-scale creativity as a mechanism which can be in competition with entrenchment in usage-based models of language change. Among the phenomena that this approach is capable of addressing there are:

1) The tendency of falling into disuse of well-established constructions.

2) Factors contributing to 'longer-lasting' constructions in the linguistic system.

3) The quantification of entrenchment inhibition as a variable counterbalancing conventionalization and grammaticalization.

4) The nature of entrenched constructions that are more likely to 'creatively' inhibited.

5) The nature of cognitive/social factors triggering attempts of dynamic resonance and entrenchment inhibition.

\section{References}

Anderson, J. R., Bothell, D., Byrne, M. D., Douglass, S., Lebiere, C., \& Qin, Y. (2004). An integrated theory of the mind. Psychological Review, 111, 1036-1060.

Beckner, Clay, Richard Blythe, Joan Bybee, Morten H. Christiansen, William Croft, Nick C. Ellis, John Holland, Jinyun Ke, Diane Larsen-Freeman, and Tom Schoenemann. 2009. "Language Is a Complex Adaptive System: Position Paper." In Language Is a Complex Adaptive System, edited by N. C. Ellis and D. L. Freeman. Chichester: John Wiley \& Sons.

Benveniste, Emile. 1958. "Subjectivity in language." In Problems in General Linguistics 223-230. Coral Gables: University of Miami Press.

Blythe, Richard A, and William Croft. 2012. "S-curves and the mechanisms of propagation in language change." Language 88 (2):269-304.

Boroditsky, Lera. 2000. "Metaphoric structuring: Understanding time through spatial metaphors." Cognition 75 (1):1-28.

Bronislaw Malinowski. 1932. Crime and custom in savage society. London: Paul, Trench, Trubner.

Brown, Penelope and Stephen C. Levinson. 1987. Politeness: Some universals in language usage. Cambridge: Cambridge University Press.

Bybee, Joan. 1998. A functionalist approach to grammar and its evolution. Evolution of Communication, 2, 249-278.

Bybee, Joan. 2002. "Lexicalization of sound change and alternating environments." In Laboratory Phonology 5: Language acquisition and the lexicon, edited by M. Broe and J. Pierrehumbert, 250-68. Cambridge: Cambridge University Press. 
Bybee, Joan. 2003. "Mechanisms of change in grammaticization: The role of frequency." In The Handbook of Historical Linguistics, edited by B. D. Joseph and J. Janda, 602-623. Oxford: Blackwell.

Bybee, Joan. 2010. Language, usage and cognition. Cambridge: Cambridge University Press. Bybee, Joan, Revere Perkins, and William Pagliuca. 1994. The evolution of grammar: Tense, aspect, and modality in the languages of the world. Chicago: University of Chicago Press.

Carter, Ronald. 2004. Language and Creativity: The art of common talk. London and New York: Routledge.

Casella, George, and Roger Berger. 2001. Statistical Inference. Pacific Grove, CA: Duxbury Press.

Clark, Herbert H. 1996. Using language, Cambridge University Press. Cambridge.

Croft, William. 2000. Explaining language change: An evolutionary approach. Harlow: Pearson Education.

Croft, William, and D Alan Cruse. 2004. Cognitive linguistics. Cambridge: Cambridge University Press.

Cruse, D. A. 2006. A glossary of semantics and pragmatics. Edinburgh: Edinburgh University Press.

Culpeper, Jonathan. 2011. Impoliteness: Using language to cause offence. Cambridge: Cambridge University Press.

De Smet, Hendrik, and Jean-Christophe Verstraete. 2006. "Coming to terms with subjectivity." Cognitive Linguistics 17 (3):365-392.

Du Bois, John W. 2014. "Towards a dialogic syntax." Cognitive Linguistics 25 (3):359-410.

Du Bois, John W, and Rachel Giora. 2014. "From cognitive-functional linguistics to dialogic syntax." Cognitive Linguistics 25 (3):351-357.

Evans, Vyvyan. 2007. A glossary of cognitive linguistics. Edinburgh: Edinburgh University Press.

Fehr, Ernst, Urs Fischbacher and Simon Gachter. 2002. Strong reciprocity, human cooperation and the enforcement of social norms. Human Nature 13: 1-25.

Bullowa, Margaret, J Fidelholtz, and A Kessler. 1975. "Infant vocalization: communication before speech." In Socialization and communication in primary groups edited by T. R. Williams. Berlin: Degruyter (pp. 253-)

Fillmore, Charles J, and Paul Kay. 1999. "Grammatical constructions and linguistic generalizations: The What's X doing Y? construction." Language 75 (1): 1-33.

Fischer, Olga. 2008. "On analogy as the motivation for grammaticalization." Studies in Language $32(2): 336-382$.

Gentner, Dedre \& Stella Christie. 2010. Mutual bootstrapping between language and analogical processing. Language and Cognition 2(2), 261-283.

Gilquin, G. 2006. 'The place of prototypicality in corpus linguistics: causation in the hot seat', in St.Th. Gries and A. Stefanowitsch (eds) Corpora in cognitive linguistics: Corpus-based approaches to syntax and lexis, pp. 159-91. Berlin: Mouton de Gruyter.

Goldberg, Adele E. 1995. Constructions: A construction grammar approach to argument structure. Chicago: University of Chicago Press.

Gouldner, Alvin W. 1960. The norm of reciprocity: A preliminary statement. American sociological review:161-178.

Grice, H. Paul. 1975. Logic and conversation. In: Peter Cole and Jerry Morgan (eds) Syntax and Semantics 3: Speech Acts. London and New York: Academic Press, pp. 41-58.

Gries, Stefan Th. 2003. "Towards a corpus-based identification of prototypical instances of constructions." Annual review of cognitive linguistics 1 (1):1-27.

Gries, Stefan Th., Beate Hampe, and Doris Schönefeld. 2010. "Converging evidence: more on the association of verbs and constructions." In Empirical and experimental methods in cognitive/functional research, edited by S. Rice and J. Newman, 59-72. Stanford, CA: CSLI.

Gries, Stefan, and Martin Hilpert. 2008. "The identification of stages in diachronic data: Variabilitybased neighbour clustering." Corpora 3 (1):59-81. 
Heine, Bernd, and Tania Kuteva. 2007. The genesis of grammar: A reconstruction. Oxford: Oxford University Press.

Haiman, John. 1994. "Ritualization and the development of language." In Perspectives on grammaticalization, edited by W. Pagliuca, 3-28. Amsterdam/Philadelphia: John Benjamins.

Hilpert, Martin. 2006. "Distinctive collexeme analysis and diachrony." Corpus Linguistics and Linguistic Theory 2 (2):243-256.

Hopper, Paul J., and Elizabeth C. Traugott. 2003. Grammaticalization. 2nd ed. Cambridge: Cambridge University Press.

Jäger, Gerhard, and Anette Rosenbach. 2008. "Priming and unidirectional language change." Theoretical linguistics 34 (2):85-113.

Kasper, Gabriele. 1990. Linguistic politeness: Current research issues. Journal of pragmatics 14 (2):193-218.

Kuperman, Victor, and Joan Bresnan. 2012. "The effects of construction probability on word durations during spontaneous incremental sentence production." Journal of Memory and Language 66 (4):588-611.

Langacker, Ronald W. 1987. Foundations of cognitive grammar: Theoretical prerequisites. Vol. I. Stanford, CA: Stanford University Press.

Langacker, R. W. 2009. Investigations in cognitive grammar. Berlin: Walter de Gruyter.

Langley, P., Cummings, K., \& Shapiro, D. 2004. Hierarchical skills and cognitive architectures. In Proceedings of the twenty-sixth annual conference of the cognitive science society (pp. 779784). Chicago, IL.

Leech, Geoffrey N. 2014. The Pragmatics of Politeness. New York: Oxford University Press .

Mahlberg, M. 2007. 'Corpus stylistics: bridging the gap between linguistic and literary studies', in M. Hoey, M. Mahlberg, M. Stubbs and W. Teubert (eds.) Text, discourse and corpora: Theory and analysis, pp. 219-46. London: Continuum.

McRae, Ken, Virginia R de Sa, and Mark S Seidenberg. 1997. "On the nature and scope of featural representations of word meaning." Journal of Experimental Psychology: General 126 (2):99.

Narrog, Heiko. 2012. "Beyond intersubjectification: Textual usages of modality and mood in subordinate clauses as part of speech orientation." English Text Construction 5 (1):29-52.

Newell, Allen. 1990. Unified theories of cognition. Cambridge, MA: MIT Press.

Nuyts, Jan. 2012. "Notions of (inter) subjectivity." English Text Construction 5 (1):53-76.

Pickering, Martin J, and Simon Garrod. 2006. "Alignment as the basis for successful communication." Research on Language and Computation 4 (2-3):203-228.

Reich, Wendelin. 2011. "The cooperative nature of communicative acts." Journal of Pragmatics 43 (5):1349-1365.

Roland, Douglas, Hongoak Yun, Jean-Pierre Koenig, and Gail Mauner. 2012. "Semantic similarity, predictability, and models of sentence processing." Cognition 122 (3):267-279.

Rosch, Eleanor, and Carolyn B Mervis. 1975. "Family resemblances: Studies in the internal structure of categories." Cognitive psychology 7 (4):573-605.

Schmid, Hans-Jörg. 2007. "Entrenchment, salience, and basic levels." The Oxford handbook of cognitive linguistics 117138.

Searle, John R. 1969. Speech acts: An essay in the philosophy of language. Vol. 626. Cambridge: Cambridge University press.

Seretan, V. and Wehrli, E. 2007. 'Multilingual collocation extraction with a Syntactic Parser', Language Resources and Evaluation 43 (1): 71-85.

Sinclair, John. 1991. Corpus, concordance, collocation. Oxford: Oxford University Press.

Spencer-Oatey, Helen. 2005. (Im) politeness, face and perceptions of rapport: unpackaging their bases and interrelationships. Journal of politeness research: Language, behaviour, culture 1 (1). doi: 10.1515/jplr.2005.1.1.95. 
Stefanowitsch, Anatol. 2008. "Negative entrenchment: A usage-based approach to negative evidence." Cognitive Linguistics 19 (3):513-531.

Stefanowitsch, Anatol, and Stefan Th Gries. 2003. "Collostructions: Investigating the interaction of words and constructions." International journal of corpus linguistics 8 (2):209-243.

Tantucci, Vittorio. 2016. "Towards a typology of constative speech acts: Actions beyond evidentiality, epistemic modality and factuality." Intercultural Pragmatics 13 (2).

Tantucci, Vittorio. 2017. "From immediate to extended intersubjectification: A gradient approach to intersubjective awareness and semasiological change." Language and Cognition 9 (1):88120.

Terkourafi, Marina. 2015. "Conventionalization: A new agenda for im/politeness research." Journal of Pragmatics 86:11-18.

Traugott, Elizabeth Closs. 2010. "Revisiting subjectification and intersubjectification." In Subjectification, intersubjectification and grammaticalization, edited by K. Davidse and L. Vandelanotte. Berlin: De Gruyter Mouton.

Traugott, Elizabeth C. 2012. "Intersubjectification and clause periphery." English Text Construction 5 (1):7-28.

Traugott, E. C., and R. B. Dasher. 2002. Regularity in semantic change. Cambridge: Cambridge University Press

Traugott, Elizabeth Closs, and Graeme Trousdale. 2013. Constructionalization and constructional changes. Oxford: Oxford University Press.

Tummers, José, Kris Heylen, and Dirk Geeraerts. 2005. "Usage-based approaches in cognitive linguistics: A technical state of the art." Corpus Linguistics and Linguistic Theory 1 (2):225-261.

Zima, Elisabeth, and Geert Brône. 2015. "Cognitive Linguistics and interactional discourse: time to enter into dialogue." Language and Cognition 7 (04):485-498.

Watts, Richard J. 1989. Relevance and relational work: linguistic politeness as politic behaviour. Multilingua 8: 131-166.

Watts, Richard J. 2003. Politeness. Cambridge: Cambridge University Press. 